\title{
Bioeconomia, economia circular e agroindústria 4.0: proposições para as transições tecnológicas emergentes
}

\author{
Bruno Gouvêa Bastos ${ }^{1}$ \\ José Carlos de Jesus Lopes ${ }^{2}$ \\ Ana Carolina Nogueira Gonçalves ${ }^{3}$ \\ Kalil Nascimento Neiva ${ }^{4}$
}

Submissão: 05/11/2021

Aceite: $10 / 12 / 2021$

\begin{abstract}
Resumo
As proposições da Bioeconomia apontam para uma transição tecnológica de uma economia baseada em energias fósseis para uma economia baseada em fontes renováveis das biomassas, um meio de sequestro de carbono. As proposições da economia circular buscam romper com o ciclo fechado extrair-produzir-descartar, alternando-se para o reaproveitamento racional dos resíduos no ciclo produtivo mais limpo. As proposições da agroindústria 4.0 trazem a conexão em rede digital, de sistemas físicos, sob o suporte da Tecnologia da Informação e Comunicação, um direcionamento alternativo de formação de cadeias produtivas agroindustriais mais sustentáveis e inteligentes. Assim, questiona-se o quanto às abordagens teóricas e às respectivas proposições tecnológicas da Bioeconomia, da economia circular e da agroindústria 4.0 estão alinhadas para o sequestro de carbono. Sob esta perspectiva, este ensaio teórico dedica-se a refletir sobre os alinhamentos das abordagens teóricas e às respectivas proposições tecnológicas da Bioeconomia, da economia circular e da agroindústria 4.0 para o sequestro de carbono. Trata-se de uma pesquisa qualitativa, descritiva, fruto de uma revisão bibliográfica, com abordagens exploratórias multi e interdisciplinares. Os resultados apontaram para a existência de uma transição da abordagem conceitual inicial da Bioeconomia para uma nova vertente, a Bioeconomia sustentável, com vista ao sequestro de carbono. Refletiu-se que as abordagens conceituais e as proposições tecnológicas da Bioeconomia sustentável estão relativamente alinhadas com as da economia circular e ambas estão igualmente relativamente alinhadas com a agroindústria 4.0. Refletiu-se também em relação às restrições evidenciadas entre as três proposições, o que significa a existência de desafios a serem superados.
\end{abstract}

Palavras-chave: Tecnologias sustentáveis e inteligentes; Sistemas de Informação; Sequestro de carbono; Agroenergia; Gestão inteligente da cadeia do agronegócio.

\section{Bioeconomy, circular economy and agroindustry 4.0: drivers to emerging technological switchs}

\begin{abstract}
The bioeconomy propositions point to an emerging technological switchs from an economy based on fossil energies to an economy based on renewable sources of biomass, toward to carbon sinks. The circular economy propositions seek to break down the closed extract-produce-discard cycle, alternating with the rational reuse of waste in the cleaner production chain. The agroindustry 4.0 propositions bring the digital network connection of physical systems, under the support of Information and Communication Technology, an alternative focused to sustainable and smart agroindustrial value chains. Thus, here is questioned how much the theoretical approaches and the respective technological propositions of bioeconomic, circular economy and agroindustry 4.0 are aligned, with carbon sinks. From this perspective, this theoretical essay focus to consider on the alignments of theoretical approaches and the respective technological propositions of bioeconomic, circular economy and agroindustry 4.0, with carbon sinks. It is qualitative research, with multi and interdisciplinary exploratory approaches. The text aims to be descriptive, found

\footnotetext{
${ }^{1}$ Mestrando em Administração Pública (Programa de Pós-Graduação Profissional em Administração Pública (PROFIAP/ESAN) da Universidade Federal do Mato Grosso do Sul (UFMS). Email: $\underline{\text { bbastos@semagro.ms.gov.br }}$

${ }^{2}$ Doutorado em Meio Ambiente e Desenvolvimento (UFPR). Professor do Programa de Pós-Graduação Profissional em Administração Pública (PROFIAP/ESAN) da Universidade Federal do Mato Grosso do Sul (UFMS).

Email:jose.lopes@ufms.br

${ }^{3}$ Graduação em Ciências Econômicas (ESAN-UFMS). Bolsista PIBIC/CNPQ/UFMS-2020-2021 (UFMS).

Email:anacarol.nogueira@hotmail.com

${ }^{4}$ Graduação em Ciências Econômicas (ESAN-UFMS). Bolsista PIBIC/CNPQ/UFMS-2020-2021 (UFMS).

Email:kalilneiva@gmail.com
}

COLÓQUIO - Revista do Desenvolvimento Regional - Faccat - Taquara/RS - v. 19, n. 1, jan./mar. 2022 
by of a bibliographic review. The results pointed to the existence of a transition from the initial conceptual approach of bioeconomic to a new dimension, sustainable bieconomic, regarding to carbon sinks. The findings recognized that the conceptual approaches and technological propositions of the sustainable bioeconomy are relatively aligned with those of the circular economy, and both are also relatively aligned with agroindustry 4.0. However, restrictions evidenced between the three propositions were warned, which means the existence of challenges to be overcome.

Keywords: Sustainable and smart technologies; Information systems; Carbon sinks; Agroenergy; Smart agribusiness chain managment.

\section{Introdução}

Estudos científicos (STERN, 2006; NOBRE et al., 2007; STOCKER et al., 2013; BRASIL, 2020a; 2020b) evidenciam que vem ocorrendo uma elevação da concentração de Gases do Efeito Estufa (GEE) na atmosfera terrestre, resultando no aquecimento do planeta e nas crises climáticas, recentemente denominadas de emergências climáticas. As principais causas apontadas para essa elevação são o modo de produção e consumo da sociedade contemporânea e as atividades antropocêntricas, como a geração de energia; as atividades empreendidas na agroindústria, em especial, no segmento agrícola e da pecuária, nas decorrentes mudanças no uso da terra (desmatamento) e nos sistemas logísticos dos transportes (LAMPIS et al., 2020; ONU, 2021).

Para enfrentar esta evidenciada crise climática, a comunidade científica e algumas partes interessadas acreditam na possibilidade da transição de uma economia baseada em combustíveis fósseis para uma economia lastreada, em sua maior parte, em recursos biológicos renováveis, sobretudo, nas biomassas. Na literatura essa possibilidade advém da proposição da Bioeconomia (GEORGESCU-ROEGEN, 1975; OECD, 2009; HEIJMAN, 2016; D'Amato, 2017; santos, 2020; SILVA; OLIVEIRA, 2020). No entendimento de Heijman (2016), a Bioeconomia está ganhando cada vez mais espaço, para discussão entre as partes interessadas, bem como e entre os tomadores de decisões dos setores que se utilizam de insumos da produção primária de base biológica, por exemplo, na cadeia do agronegócio.

Mccormick e Kautto (2013) ressaltam que, em resposta aos desafios da sociedade, como mudanças climáticas, escassez de recursos naturais e poluição ambiental, demandam-se transformadoras mudanças rumo a sistemas sustentáveis de produção e consumo. Completam os mesmos autores que a Bioeconomia, compreendida como uma economia de base biológica, representa significativa mudança nos sistemas socioeconômicos, agrícolas, energéticos e técnicos, atendendo ainda muito dos requisitos de sustentabilidade (nas perspectivas ambiental, social e econômica), caso projetada e implantada de forma inteligente. 
Sob esta perspectiva, a economia circular (D'AMATO, 2017; ABDALLA; SAMPAIO, 2018; SEHNEM; PEREIRA, 2019; DGAE, 2020; ELLEN MACARTHUR FOUNDATION, 2020) se coloca como um modelo sociotécnico que propõe que o valor dos recursos extraídos e produzidos seja mantido em circulação através de cadeias produtivas integradas. Geissdoerfer et al. (2017) definem economia circular como um sistema regenerativo, em que a entrada de recursos e saída de resíduos, emissões e energia são minimizados pela desaceleração, fechamento e estreitamento de loops de materiais e energia. Os mesmos autores apontam que tais objetivos podem ser alcançados por meio de design, manutenção, reparo, reutilização, remanufatura, recondicionamento e reciclagem. Carus e Dammer (2018) ressaltam que, embora os conceitos de Bioeconomia e economia circular possuam metas semelhantes e, até certo ponto, se sobreponham, nenhum conceito é totalmente parte de outro, nem tampouco embutido no outro.

Desde o início da industrialização, saltos tecnológicos (três revoluções industriais) levaram a mudanças de paradigmas. Com base em uma digitalização cada vez mais avançada nas fábricas, combinada a tecnologias que comungam internet e objetos inteligentes, além de sistemas de produção modulares e eficientes, em que produtos controlam seu próprio processo industrial, vislumbra-se que atualmente a sociedade caminha pela Quarta Revolução Industrial, também denominada Indústria 4.0 (BLUNCK; WERTHMANN, 2017; MORRAR; ARMAN; MOUSA, 2017; SOUSA JABBOUR; et al., 2018; COTEC, 2019; BMWI, 2020).

Relatório desenvolvido pela COTEC Portugal e a Universidade Católica Portuguesa (COTEC, 2019) aduz que a adoção da digitalização representa a melhor estratégia para transitar definitivamente de uma economia fóssil linear para uma Bioeconomia circular. Assim, segundo o mesmo relatório, aliar os princípios da Bioeconomia e da economia circular com as mais-valias das tecnologias digitais e de informação podem tornar os processos produtivos e de coleta/utilização de biomassa mais eficientes, bem como reduzir os desperdícios e aumentar a aplicabilidade/utilização dos novos biomateriais pelo consumidor final.

Sendo assim e a partir dessas perspectivas conceituais e proposições tecnológicas, todas essas propostas voltadas às mudanças dos padrões de consumo e de produção da sociedade contemporânea e das decorrentes atividades antropocêntricas, até aqui vivenciadas e experimentadas, podem ser concebidas por uma outra racionalidade ambiental (LEFF, 2009; 2013; VEIGA, 2010). Ou seja, um outro modelo societal direcionador para a mitigação das mudanças climáticas e para o alcance do paradigma do Desenvolvimento Sustentável (CMMAD, 
2009), que tem como princípio o atendimento das dimensões da sustentabilidade (ELKINGTON, 2001; SACHS, 2002; VEIGA, 2011, ONU, 2015; 2020).

Nesse contexto, questiona-se o quanto as abordagens teóricas e as respectivas proposições tecnológicas da Bioeconomia, da economia circular e da agroindústria 4.0 estão alinhadas, para o sequestro de carbono. Sob esta perspectiva, este ensaio teórico dedica-se a refletir sobre os alinhamentos das abordagens teóricas e às respectivas proposições tecnológicas da Bioeconomia, da economia circular e da agroindústria 4.0 para o sequestro de carbono.

Espera-se que os resultados a serem alcançados por este estudo possam contribuir para outras reflexões alternativas para atender a emergência climática, entre os pares, acerca das três proposições. Para tanto, o corpo textual deste ensaio teórico segue a seguinte ordem. Inicia-se com esta parte introdutória, que traz a devida anunciação da problemática central da pesquisa e a respectiva declaração do objetivo geral. Em seguida, os aspectos metodológicos são brevemente explicados, para logo após as revisões teóricas concernentes à Bioeconomia, economia circular e a agroindústria 4.0 serem apresentadas e analisadas. As considerações finais são acompanhadas pelas referências que deram as sustentações teóricas inter e multidisciplinares.

\section{Aspectos metodológicos}

Trata-se de um estudo com objetivos descritos e exploratórios (GIL, 2017; e MARCONI \& LAKATOS, 2018), uma vez que esta investigação científica descreve as abordagens conceituais dos termos Bioeconomia, economia circular e agroindústria 4.0 e explora as abrangências desses termos, à luz das dimensões da sustentabilidade e do uso racional das Tecnologias de Informação e Comunicação (TIC). A técnica de análise de dados é a qualitativa (MARCONI \& LAKATOS, 2018). Converte-se numa pesquisa bibliográfica (GIL, 2017), portanto, constituída por levantamento de dados secundários, advindos de obras seminais, acompanhadas de artigos, publicados em periódicos.

A pesquisa foi delineada à luz da abordagem epistemológica multi e interdisciplinar, já explicada por Japiassú (1976), e utilizada nas pesquisas de Niles e Lubell (2012), Nascimento (2014) e Dantas e Passador (2020), face ao entendimento consensual de diversos pesquisadores, cujas discussões temáticas ligadas à sustentabilidade oportunizam análises, pelas diversas lentes dos saberes científicos, uma nova racionalidade que permite integrar o maior número de variáveis que integram o contexto socioambiental e obter assim uma visão integrada das interrelações entre as abordagens teóricas tratadas. 
Trata-se de uma comunicação científica, no formato textual de um ensaio teórico (MENEGUETTI, 2011; SOARES, PICOLLI; CASAGRANDE, 2018). Boscov e Rezende (2017); Oliveira e Passador (2019); Vogt; Bill e Silva (2019) utilizaram-se do modelo textual de ensaio teórico, seguindo os apontamentos de Meneguetti (2011), para escrever os resultados das suas reflexões frutos das suas pesquisas empreendidas. Ainda para esses mesmos autores, o ensaio teórico comporta a liberdade desejada pelos autores-pesquisadores para comunicar, cientificamente, os achados das suas pesquisas bibliográficas, sem a obrigatoriedade de adotar um padrão fixo ou um modelo rígido de organização do corpo textual, diferente de outros modelos bem formais de comunicações científicas. Mesmo assim, as normas da ABNT (2018) foram empregadas, ao longo deste corpo textual.

\section{Abordagens e abrangências conceituais da proposição científica da Bioeconomia}

Molesti (2006) identifica Nicolas Georgescu-Roegen (1975) como o primeiro autor a difundir o termo Bioeconomia, uma vez que na década de 1970 , ele já considerava que a economia e a ecologia um dia se fundiriam, e que o domínio fenomênico coberto por esta última seria mais amplo do que o abrangido pela primeira. Dias e Carvalho Filho (2017) explicam que à luz da corrente sistêmica (MORIN, 2003; BERTALANFFY, 2015) que se sustenta a Bioeconomia, a natureza atuaria como fator limitante do processo econômico, dada às complexas resiliências dos ecossistemas (VASCONCELLOS, 2002), sendo os arranjos tecnológicos inseridos em qualquer na cadeia produtiva incapazes de encontrar, ad infinitum, um substituto direto para o suprimento dos recursos naturais, escassos (VEIGA, 2011).

A literatura descreve que ao longo das últimas quatro décadas, a visão a respeito da Bioeconomia tem se modificado, graças ao surgimento de inovações relacionadas ao uso de produtos e processos biológicos, em diversas áreas, como a biotecnologia. Para Dias e Carvalho Filho (2017), o avanço da biotecnologia tem sido responsável por melhorar a eficiência ambiental da produção primária e do processamento industrial. Embora, o termo Bioeconomia ainda careça de um conceito único (D'AMATO, 2017; MARCIAL et al., 2017; MEIJAS, 2019; SANTOS et al., 2020; SILVA; OLIVEIRA, 2020), algumas iniciativas de concepções das abordagens conceituais trazem consigo características de interesses das partes interessadas que as constroem. Por exemplo, na concepção da Organização para a Cooperação e Desenvolvimento Econômico (OCDE, 2009, pág. 8, tradução nossa):

Uma Bioeconomia pode ser pensada como um mundo onde a biotecnologia contribui para uma parcela significativa da produção econômica. É provável que a emergente Bioeconomia envolva três elementos: o uso de conhecimentos avançados de genes e 
processos celulares complexos para desenvolver novos processos e produtos; o uso de biomassa renovável e bioprocessos eficientes para apoiar a produção sustentável; e a integração do conhecimento biotecnológico e aplicação entre setores.

Ainda à luz dos interesses das instituições supranacionais, pode-se ilustrar a abordagem conceitual concebida pela Comissão Europeia (2018, pág.1), organização mundial que representa e defende os interesses da União Europeia. Para ela:

A Bioeconomia abrange todos os setores e sistemas que dependem de recursos biológicos (animais, plantas, microrganismos e biomassa derivada, inclusive resíduos orgânicos), suas funções e princípios. Ela inclui e interliga terra e ecossistemas marinhos e os serviços que eles fornecem; todos os setores da produção primária que utilizam e produzem recursos biológicos (agricultura, silvicultura, pesca e aquicultura); e todos os setores econômicos e industriais que utilizam recursos e processos biológicos para a produção de alimentos, rações, produtos de base biológica, energia e serviços.

Sob essas perspectivas que refletem sobre as abordagens conceituais, Lewandowski (2018) observa bem, que a proposição científica da Bioeconomia, muitas vezes referida como economia de base biológica, engloba a produção de recursos de base biológica e sua conversão em alimentos, rações, bioenergia e materiais de base biológica. Assim, para o mesmo autor, uma cadeia de valor de base biológica inclui a produção primária de recursos naturais e a sua conversão resulta em bens de maior valor agregado, por meio de seu processamento e comercialização no mercado. No Brasil, o Ministério da Ciência, Tecnologia, Inovações e Comunicações (MCTIC, 2018, pág. 12) conceitua o termo Bioeconomia como:

o conjunto de atividades econômicas baseadas na utilização sustentável e inovadora de recursos biológicos renováveis (biomassa), em substituição às matérias-primas fósseis, para a produção de alimentos, rações, materiais, produtos químicos, combustíveis e energia produzidos por meio de processos biológicos, químicos, termoquímicos ou físicos, promovendo a saúde, o desenvolvimento sustentável, o crescimento nacional e o bem-estar da população.

No que diz respeito ao Brasil, em relação à concepção conceitual do termo, Marcial et al. (2017, pág. 87) ressaltam a abrangência que o termo Bioeconomia oportuniza, em função do reconhecido fortalecimento da relação entre agricultura e da agroindústria, com potencial para contribuir para o desenvolvimento econômico das regiões produtoras do País. Os mesmos autores ainda defendem que, "a base apresenta como uma grande oportunidade na promoção do desenvolvimento, transformando antigas commodities em produtos com alto valor agregado", ainda, quando o Brasil se coloca como um potencial exportador de diversos tipos de commodities derivadas da biomassa.

Sob essa perspectiva de trocas internacionais, Moreira (2016) destaca que, sendo o território brasileiro que comporta a maior biodiversidade do planeta, o País posiciona-se em uma 
situação favorável à abrangência de inúmeros produtos e processos relacionados a setores ligados à proposição científica da Bioeconomia, como a produção de energia renovável, alimentos funcionais e biofortificados, biopolímeros e cosméticos. Sob esta perspectiva, há de se refletir que a Bioeconomia se apresenta como uma nova e promissora vertente econômica, abrindo possibilidades reais para o aproveitamento sustentável desta biodiversidade, com possibilidades de dinamizar segmentos essenciais da economia brasileira.

Por tudo isso, com maior cautela, há de se investigar as limitações e desafios para que o Brasil alcance esta performance, em função do reconhecimento da estrutura produtiva e das demais forças (endógenas e exógenas) que atuam ao longo da cadeia do agronegócio brasileiro. Beraldo (2019) aponta as abrangências, reconhece as oportunidades e, igualmente, as limitações e os desafios para a Bioeconomia, no Brasil (Quadro 1).

Quadro 1 - Abrangências, oportunidades e limitações e desafios da Bioeconomia, no Brasil

\begin{tabular}{|c|c|c|}
\hline Abrangenclas & & \\
\hline \multirow{3}{*}{$\begin{array}{l}\text { País mega diverso, } \\
\text { com seis biomas } \\
\text { distintos, abundância } \\
\text { de água potável e rica } \\
\text { em biodiversidade; }\end{array}$} & & \multirow{2}{*}{$\begin{array}{l}\text { Investimento em recursos humanos; } \\
\text { Monitoramento das condições } \\
\text { edafoclimáticas e das externativas negativas } \\
\text { que impactam os setores produtos, sociais e } \\
\text { ambientais; }\end{array}$} \\
\hline & \multirow{3}{*}{$\begin{array}{l}\text { Novas fontes proteicas } \\
\text { alimentícias para atender a } \\
\text { segurança alimentar e nutricional } \\
\text { (proteínas alimentícias derivadas } \\
\text { de plantas, de fermentação e as } \\
\text { cultivadas); }\end{array}$} & \\
\hline & & \\
\hline \multirow{2}{*}{$\begin{array}{l}\text { Forte em importantes } \\
\text { áreas da Bioeconomia: } \\
\text { biotecnologia, } \\
\text { bioenergia (ou } \\
\text { biorrefinarias) e } \\
\text { biodiversidade; }\end{array}$} & & \\
\hline & \multirow{2}{*}{$\begin{array}{l}\text { Potencial elevado de criar } \\
\text { empregos e renda, com base na } \\
\text { aplicação de conhecimento e } \\
\text { novas tecnologias, em especial } \\
\text { com o uso da biodiversidade; }\end{array}$} & \multirow{3}{*}{$\begin{array}{l}\text { Altas volatilidades das cotações internacionais } \\
\text { e dos preços domésticos das commodities } \\
\text { agrícolas, com potencializar vetores } \\
\text { tecnológicos que alternam a produção de } \\
\text { bens alimentícios para a produção de insumos } \\
\text { às fontes alternativas de energias, que } \\
\text { venham a compor as matrizes energéticos; }\end{array}$} \\
\hline & & \\
\hline & \multirow{7}{*}{$\begin{array}{l}\text { Tradicionalmente, já se tem em } \\
\text { estágio mais consolidados os } \\
\text { segmentos ligados aos segmentos } \\
\text { da: energia (biogás e os } \\
\text { biocombustíveis); biomateriais } \\
\text { (biofibras, biomassas, bioplásticos, } \\
\text { biocompostos); bioprodutos } \\
\text { (extensivamente sobre alimentos } \\
\text { humanos e para animais); e os } \\
\text { bioquímicos (ácidos láticos e } \\
\text { succínicos); }\end{array}$} & \\
\hline & & Avanço na proteção aos direitos de \\
\hline , & & de \\
\hline \multirow{2}{*}{$\begin{array}{l}\text { Baixos custos da } \\
\text { produção de } \\
\text { biomassa; }\end{array}$} & & \\
\hline & & \multirow{2}{*}{$\begin{array}{l}\text { O uso racional e adequado do solo agrícola e } \\
\text { agropastoril; }\end{array}$} \\
\hline \multirow{4}{*}{$\begin{array}{l}\text { Disponibilidade de } \\
\text { importantes centros } \\
\text { de pesquisa, } \\
\text { desenvolvimento e } \\
\text { inovação (PD\&I) e } \\
\text { empresas líderes em } \\
\text { setores da } \\
\text { Bioeconomia. }\end{array}$} & & \\
\hline & & \multirow{2}{*}{$\begin{array}{l}\text { Escalas de produção em territórios produtivos } \\
\text { regulados e com práticas de produção de bens } \\
\text { agrícolas e de criação de animais sustentáveis; }\end{array}$} \\
\hline & \multirow[b]{2}{*}{$\begin{array}{l}\text { Impactos positivos e criação de } \\
\text { novos modelos de negócios sobre } \\
\text { vários segmentos da economia: } \\
\text { alimentos, novas energéticas } \\
\text { alternativas, segmentos da saúde, } \\
\text { farmacêutica, indústria química. }\end{array}$} & \\
\hline & & \\
\hline
\end{tabular}

Fonte: Com base em Beraldo (2019), complementado pelos aportes reflexivos obtidos das revisões teóricas (2021). 
A pesquisa interdisciplinar é baseada na colaboração de diferentes disciplinas em toda a cadeia de valor de base biológica, incluindo as Ciências Naturais, as Ciências Econômicas e as Ciências Sociais. Essa pesquisa consiste em uma abordagem sistêmica (MORIN, 2003; VASCONCELOS, 2002), que permite a avaliação de desafios complexos, por meio das perspectivas social, ambiental e econômica e demais dimensões postuladas por Sachs (2002). Já as abordagens transdisciplinares (JAPIASSÚ, 1996; NILES \& LUBELL, 2012) comportam o anseio da proposição emergente da Bioeconomia em contribuir na superação de alguns dos mais relevantes desafios sociais, atentando assim para as dimensões social, ambiental, cultural, institucional, político (nacional e internacional), territorial, ecológico, integrantes e indissociáveis do princípio da sustentabilidade (ELKINGTON, 2000; SACHS, 2001).

\section{A proposição científica da Bioeconomia em transição para a vertente emergente da Bioeconomia sustentável}

Com base na literatura consultada, foi perceptível um processo de mudança no construto conceitual da proposição científica gênese da Bioeconomia, postulada por Georgescu-Roegen (1975). Para uma proposição científica, em transição concebida como Bioeconomia sustentável (MARCIAL et al., 2017; COMUNIDADE EUROPEIA, 2018), face ao entendimento de que o fato de produzir bens agrícolas de biomassas de natureza renováveis, a exemplo da cultura da soja, do milho, do algodão e até mesmo das florestas artificiais de eucaliptos ou de pinhos, não necessariamente caracterizam tais atividades agroindustriais (criação de animais e produção de biomassas renováveis, como fontes de alimentos e de energias) como sustentáveis. É sob este conceito, que esta pesquisa alerta que a Bioeconomia por si só não a caracteriza como sustentável (D’AMATO, 2017). Ao concordar com Gonçalves et al. (2020), reforça aqui a reflexão de que a prática da Bioeconomia tem que ser sustentável.

Sob esta perspectiva reflexiva, todo esse avanço das proposições tecnológicas, aqui refletidas, voltadas à criação de animais e de produção agrícolas como fontes proteicas e de alimentos poderão ser, inclusive, fomentadas por políticas públicas destinadas para empreendimentos sustentáveis. Essas culturas produtivas de biomassas precisam ser emancipadas pelas dimensões da sustentabilidade.

Assim sendo, a cadeia produtiva que integram as abrangências da Bioeconomia precisa adotar de forma efetiva e com afetividade tecnologias sustentáveis e modelos de gestão socialmente mais responsáveis, para então poder ser concebida, cientificamente, como uma 
Bioeconomia sustentável, cujo modelo societal promova externalidades positivas para as dimensões que constituem o princípio da sustentabilidade (ELKINGTON, 2001; SACHS, 2002). Por extensão, para a proposição científica emergente da Bioeconomia sustentável na superação dos desafios dos Objetivos do Desenvolvimento Sustentável (ONU, 2015), estando, desta vez, a Bioeconomia sustentável auxiliada e complementada pelos saberes da Ciência e Tecnologia e Inovação (CTI). Desta forma, a Bioeconomia sustentável é, também, compreendida como uma proposição científica emergente, ao considerar as relações existentes positivas e que, por princípio, que atendam às dimensões da sustentabilidade, bem como propõem ações alternativas que façam com que os atores globais e locais ajudem-se, de forma mútua, em parcerias,

Diante do exposto, há de se concordar com Marcial et al. (2017) quando eles admitem que a diferença entre a Bioeconomia original e a sua vertente para a Bioeconomia sustentável, na qualidade de ser emergente, reside no fato de que esta última tem por base o uso intensivo de novos conhecimentos científicos e tecnológicos. Estes, contribuem para o desenvolvimento de processos mais limpos, com base biológica e para a transformação de recursos naturais em bens e serviços ecossistêmicos.

\section{Abordagens e abrangências conceituais da economia circular}

A revolução industrial e o subsequente acelerado crescimento tecnológico mundial permitiram que a sociedade obtivesse acesso a produtos com níveis de conforto material inimagináveis para as gerações anteriores, em que as matérias-primas e as fontes de energias eram concebidas como infinitas, a mão de obra prontamente disponível e os bens produzidos em massa. Esta forma de pensar enquadra-se no construto teórico da economia linear (ELLEN MACARTHUR FOUNDATION, 2020). Este construto teórico é amparado pelo modelo de produção dominante de take-make-waste (VELEVA; BODKIN; TODOROVA, 2017), ou seja, "extrair-produzirutilizar-descartar" (RIBEIRO, 2018, pág. 90). Para Abdalla e Sampaio (2018), o conceito de economia circular afasta-se completamente da concepção da produção da economia linear. Os autores propõem intensas modificações estruturais ao confrontar-se com o sistema tradicional e já consolidada visão da economia linear. Eles apontam para a economia circular, as práticas conceitualmente fundamentadas na lógica mais racional dos contínuos reparos e reúsos, remanufaturas e superciclagem. 
Para a Direção Geral das Atividades Econômicas da República Portuguesa (DGAE, 2020), a economia circular constitui-se em um conceito estratégico, cujas proposições tecnológicas se assentam nos princípios de uma nova racionalidade que potencializa as ações contínuas da redução, reutilização, recuperação e reciclagem de materiais e energias. Esta outra racionalidade apresenta-se como um elemento chave alternativo para promover a dissociação entre o crescimento econômico e o aumento no consumo de recursos, sobretudo, os finitos. Para o Conselho Mundial de Negócios para o Desenvolvimento Sustentável (WBCSD, 2017), a nova racionalidade advinda da economia circular distancia-se do modelo econômico e raciocínio tradicional, e nada sustentável, que consiste mecanicamente em extrair-produzir-descartar. Passa a adotar, então, um modelo regenerativo por natureza e que objetiva, tanto quanto possível, reter valor de recursos, produtos, peças e materiais, criando um sistema que permite alongamento da vida útil, reutilização ótima, reforma e reciclagem.

Desta forma, as proposições tecnológicas da economia circular propõem a reinserção dos materiais no ciclo produtivo, objetivando mitigar sua deposição no ambiente e, logo, evitar a geração de negativos impactos ambientais (FOSTER; ROBERTO; IGARI, 2016). A economia circular transforma mercadorias que estão no final de sua vida útil em recursos para terceiros, fechando ciclos em ecossistemas industriais e minimizando os desperdícios.

Como se percebe, na literatura há uma mudança na lógica econômica, algo próximo a reutilize o que puder, recicle o que não pode ser reutilizado, bem como repare o que está quebrado, além de poder remanufaturar o que não pode ser reparado (STAHEL, 2016). No Plano de Ação da União Europeia para a Economia Circular (COMISSÃO EUROPEIA, 2015), considera-se que a transição de um pensamento sistêmico baseado na economia linear para uma economia circular, bem mais sustentável, em que os valores e os atributos constituintes dos produtos, materiais e recursos se mantêm na economia o máximo de tempo possível. Ou seja, a redução da produção de resíduos e o reuso dos mesmos no ciclo produtivo representam contribuições positivas fundamentais para os esforços da União Europeia, no sentido de desenvolver uma economia sustentável, hipocarbônica, eficiente em termos de recursos e, portanto, na redução na produção de resíduos e redução de emissões associadas ao GEE, uma ação direta de sequestro de carbono. 


\section{Alinhamentos teóricos e as proposições tecnológicas entre a Bioeconomia sustentável e a economia circular}

Conforme a literatura consultada, as publicações científicas já estão relacionando os alinhamentos teóricos e as proposições tecnológicas entre a Bioeconomia com a economia circular (D`AMATO, 2017). Mais ainda. Já é possível conceber os alinhamentos teóricos e as proposições tecnológicas entre a Bioeconomia sustentável e a economia circular, em direção à Bioeconomia circular (COMISSÃO EUROPEIA, 2015). Para essa comunidade, na medida em que os materiais de base biológica possam servir para uma vasta gama de produtos e utilizações energéticas, a Bioeconomia sustentável oferece alternativas aos produtos e energias, baseados em combustíveis fósseis, para o melhor e mais racionais reusos dos recursos naturais podendo contribuir para a economia circular. Por sua vez, os materiais de base biológica podem ainda apresentar vantagens relacionadas às suas renovabilidades, biodegrabilidades ou possibilidades de compostagens baseados em recursos naturais renováveis, como a produção de cadeias produtivas constituídas de biomassas.

Em uma economia circular, deverá ser promovida, quando adequada, a utilização em cascata de recursos renováveis ou derivados de fontes energéticas baseadas de biomassas renováveis mais limpas e que atendam às dimensões da sustentabilidade. O processo construtivo da economia circular fundamenta-se por vários ciclos de reutilização e reciclagem dos produtos e subprodutos das linhas de produção ou mesmo das cadeias produtivas que integram todo o ciclo produtivo de um produto (EIP-AGRI, 2015). Os mesmos autores ainda mencionam algumas características especiais da Bioeconomia sustentável, no contexto da economia circular:

\footnotetext{
- A Bioeconomia (sustentável, grifo nosso) fornece carbono renovável para a indústria e pode substituir diretamente o carbono fóssil em quase todas as aplicações, o que não ocorre com minerais e metais;

- É um desafio manter o valor da biomassa durante o aproveitamento em cascata, o que é muito mais fácil com metais e minerais; e

- A reciclagem orgânica ainda necessita encontrar sua posição na economia circular, por exemplo, por meio de uma nova legislação sobre fertilizantes, incluindo os de base biológica.
}

Carus e Dammer (2018) explicam que a Bioeconomia sustentável e a economia circular compartilham alguns princípios comuns, de algumas proposições tecnológicas. Estes são: 1) um mundo mais sustentável e eficiente, em termos de recursos, com uma pegada de baixo carbono; e 2) ambas as proposições evitam o uso adicional de carbono fóssil, contribuindo com as metas 
climáticas, em destaque o sequestro de carbono. Para eles, a economia circular fortalece a eficiência no uso de recursos e na utilização de materiais reciclados para reduzir o uso adicional de carbono fóssil (incorporado no material ou emitido durante os processos de extração ou fabricação). Já a Bioeconomia sustentável substitui o carbono fóssil por carbono renovável de biomassa da agricultura, silvicultura e meio ambiente marinho (incluindo subprodutos e resíduos da agropecuária, da indústria e mesmo do setor de serviços urbanos).

Ainda para os mesmos autores, as abordagens e as abrangências conceituais das lógicas das proposições tecnológicas Bioeconomia e a economia circular possuem os seguintes arranjos mais sustentáveis: a) ecoeficiência; b) baixa pegada dos GEE; c) redução da demanda por carbono fóssil; d) valorização de resíduos. Neste sentido, a Bioeconomia circular, definida como a intersecção da Bioeconomia sustentável e a economia circular, incluem produtos de base biológica, o compartilhamento, a reutilização, a remanufaturação e a reciclagem dos resíduos e sobras. Além disso, fazem o uso em cascata, do reaproveitamento da cadeia de resíduos orgânicos, das cadeias de valor com eficiência de recursos, da reciclagem orgânica e da ciclagem de nutrientes.

Quadro 2 - Comparativo das proposições tecnológicas entre a Bioeconomia sustentável e a economia circular

\begin{tabular}{|l|l|}
\hline \multicolumn{1}{|c|}{ Bioeconomia } & \multicolumn{1}{|c|}{ Economia Circular } \\
\hline Pode ser Linear ou Circular. & Reciclagem intrínseca e ciclos de feedback. \\
\hline $\begin{array}{l}\text { Apenas produtos e sistemas de base } \\
\text { biológica renovável; }\end{array}$ & $\begin{array}{l}\text { Aplica-se a toda linha de produção; } \\
\text { Aplica-se a toda cadeia de produção e consumo; } \\
\text { Aplica-se a todo circuito econômico. }\end{array}$ \\
\hline $\begin{array}{l}\text { Depende dos setores primários - ênfase } \\
\text { em agregar valor às matérias-primas com } \\
\text { forte conhecimento e desenvolvimento } \\
\text { técnico. }\end{array}$ & $\begin{array}{l}\text { Agregar valor aos resíduos, perdas e sobras; e } \\
\text { Cocriar valor aos resíduos das linhas de produção e do } \\
\text { consumo. }\end{array}$ \\
\hline
\end{tabular}

Fonte: Os autores (2021), a partir das inspirações epistemológicas do EIP-AGRI (2015) e das revisões teóricas.

Longe de uma conclusão sobre as reflexões das abordagens e das abrangências da relação entre os aportes teóricos e das densidades tecnológicas mais limpas aportadas pela Bioeconomia sustentável e a economia circular, o quadro 2, a seguir, organiza um comparativo textual entre as perspectivas tecnológicas da Bioeconomia sustentável e da economia circular. 


\section{Abordagens e abrangências conceituais da agroindústria 4.0}

Henning (2013) destaca os quatro estágios das revoluções industriais, vivenciadas pela humanidade contemporânea. A primeira teve início com a implantação de novas instalações de manufaturas mecânicas, movidas à água e à vapor. A segunda aconteceu de forma complementar a primeira, pela adoção da produção em massa movida à eletricidade, associada ao uso de novas fontes de energias (o petróleo na substituição do carvão vegetal), alinhada com uma revisão técnico-operacional da divisão do trabalho. Em seguida, com o uso de eletrônica e da Tecnologia da Informação (TI) dando maior densidade tecnológica nas linhas de produção ficou caracterizada como a terceira. Por fim, a quarta, em transição, está sendo considerada com a potencialização dos sistemas ciberfísicos, não somente nos ciclos produtivos, mas igualmente, para os indivíduos, a denominada internet das coisas (ALBERTIN; ALBERTIN, 2017; CARRION; QUARESMA, 2019). De acordo com Souza, Taira, Park (2019, p. 2), o conceito de Indústria 4.0, chamado também de Cyber Phisical Integration ou Quarta Revolução Industrial pode ser definido como sendo, "um conjunto de sistemas físicos conectados a uma rede (sistemas embarcados e internet) que detêm um alto nível de integração entre produtos e processos, em que os elementos da cadeia produtiva têm a característica 'smart' como um pré-requisito". O Ministério Federal da Economia e Energia da Alemanha (BMWI, 2020) concebe a Indústria 4.0 como uma rede inteligente de máquinas e processos na indústria, com o auxílio da Tecnologia da Informação e Comunicação (TIC).

O arranjo tecnológico e social da Indústria 4.0 permite uma produção mais flexível, a exemplo da construção de fábricas em módulos, com soluções customizadas para o cliente, comportada por uma logística otimizada. A partir deste conjunto de bases digitais, potencializase a melhor utilização de dados sobre o processo produtivo e estado de um produto. Estudos da Direção Geral de Políticas Internas do Parlamento Europeu (EUROPEAN PARLIAMENT, 2016) esclarecem que, na Indústria 4.0, a organização dos processos produtivos é descrita com base em tecnologia e dispositivos que se comunicam autonomamente uns com os outros, ao longo da cadeia de valor. No entendimento de Coelho (2016), um dos pilares da Indústria 4.0 é a Internet das Coisas e se refere a objetos físicos e virtuais conectados à internet, impulsionado pelo aparecimento e uso generalizado de sensores cada vez menores e baratos, bem como um avanço em dispositivos móveis, comunicações wireless e tecnologias cloud. Ainda para ele, o termo Bigdata é característico também da Indústria 4.0. 
O termo refere-se a grandes quantidades de dados, armazenados a todo instante, resultante da existência de milhões de sistemas ligados à rede, produzindo dados em tempo real sobre praticamente tudo e inteiramente disponíveis. Em se tratando da implementação da Indústria 4.0 em indústrias brasileiras, a Federação das Indústrias do Estado do Rio de Janeiro (FIRJAN, 2016) elenca os seguintes desafios: 1) obter políticas estratégicas inteligentes, incentivos e fomentos governamentais; 2) reunir empresários e gestores industriais com visão, arrojo e postura proativa; e 3) dispor de desenvolvimento tecnológico e formação de profissionais altamente qualificados por parte das instituições acadêmicas e de pesquisa, preferencialmente com grande proximidade à indústria.

A expressão agronegócio, comumente chamado de agro ou agribusiness refere-se ao conjunto das operações de produção e distribuição de suprimentos agrícolas, às operações de produção que ocorrem na fazenda, bem como ao armazenamento, processamento e distribuição dos produtos agrícolas e seus derivados (FEIX; LEUSIN JÚNIOR, 2016). Sob esta perspectiva, o agronegócio envolve a produção de insumos para a agropecuária, a própria produção agropecuária, o processamento de produtos agropecuários, e o comércio, transporte e demais serviços realizados de forma que os produtos alcancem o consumidor final (CEPEA, 2017). Já o termo agroindústria comporta diversas definições, pois compreende vários ramos industriais, o que acaba por gerar variados graus de abrangência para o conceito (SANTOS, 2018). Para Oliveira (2016, pág. 23), em sentido amplo, a agroindústria consiste em uma:

unidade industrial de beneficiamento e/ou transformação de produtos de origem agrícola. No contexto da moderna agricultura, insere nos chamados 'complexos agroindustriais', sendo definida também, como 'indústria processadora de matériasprimas agrícolas', ou simplesmente, 'indústria da agricultura'. Trata-se, pois, de estabelecimento industrial - de pequeno, médio ou grande porte - cuja matéria-prima advém da atividade agropecuária.

Observa Parré (2000) que a agroindústria, que faz parte do complexo agroindustrial, representa o setor que transforma ou processa matérias-primas agropecuárias em produtos elaborados, adicionando valor ao produto. Para o mesmo autor, no agronegócio brasileiro as atividades são diferenciadas e interligadas, em que um setor produz insumos máquinas e equipamentos agrícolas (antes da porteira); um setor é responsável pela produção agropecuária (dentro da porteira); e um setor atua depois da porteira, envolvendo o processamento e acondicionamento, além da armazenagem e distribuição. 
O conceito de uma agricultura 4.0 persegue a lógica da Indústria 4.0 (BONONI; POLLI, 2020). A indústria 4.0 contempla empresas com novas tecnologias, por meio de uma fabricação mais ágil na linha de produção e inovação de processos, sendo que a maioria das empresas ligadas ao agronegócio já adotaram esse novo modelo de indústria. Ou seja, no setor agroindustrial já adentramos na era da agroindústria 4.0, onde a conectividade entre dispositivos integrados em sistemas de gestão torna-se crucial para diferentes modelos de negócios (GARCíABAQUERO, 2020). Conforme já analisado, os conceitos da Indústria 4.0 e manufatura inteligente são relativamente novos e contemplam a introdução de tecnologias digitais na indústria da transformação, estendendo-se ao agronegócio e à agroindústria (DE ANDA-LOPES et al., 2020), sobretudo quando a agricultura atual não apenas enfrenta o desafio de alimentar a população mundial, mas também o de fornecer biocombustíveis mais limpos.

Para Massruhá et al. (2020), os novos desafios da agroindústria 4.0 impõem a necessidade de maior produtividade e eficiência socioambiental, otimizando do uso de recursos naturais, sociais e ambientais, demandando o uso de diferentes tecnologias digitais, em que a integração de tecnologias mais limpas permite desenvolver soluções para automação, fazendas inteligentes, sanidade animal e vegetal, gestão de risco agrícola, biotecnologia, nanotecnologia, mitigação das mudanças climáticas, Bioeconomia, bioinsumos, certificação e rastreabilidade, agricultura de precisão, economia de baixo carbono, entre outras áreas de interesse.

No que tange ao caso brasileiro, uma Nota Técnica da CNI (2018), a respeito de riscos e oportunidades para o país diante de inovações disruptivas no setor de agroindústrias, menciona que as empresas de maquinaria agrícola transformam os tratores em hardwares para aplicativos cada vez mais abrangentes. Além disso, o georreferenciamento e a navegação por GPS iniciaram a transição para uma agricultura de precisão. E, ainda, o apoio de sensores, drones e sistemas de informação sobre o clima também indica o início de uma era da agricultura digital (ou agricultura 4.0), em que as empresas de maquinaria estão em posição privilegiada para gerir este conjunto de inovações, dando características mais sustentáveis aos bens agrícolas.

\section{Alinhamentos teóricos e as proposições tecnológicas entre a Bioeconomia sustentável, a economia circular e a agroindústria 4.0}

Para além das abordagens conceituais a respeito do termo agroindústria, na literatura são encontradas aplicações práticas advindas de sua definição, no campo econômico, social e ambiental, inclusive na sua relação com os conceitos bioeconômicos e da economia circular, seja na utilização da produção agrícola renovável para fins industriais, seja no aproveitamento de 
resíduos advindos da agroindústria. Silva, Pereira e Martins (2018) observam que uma das melhores oportunidades para o desenvolvimento brasileiro reside na Bioeconomia, em razão não só da pressão social por uma produção que garanta a sustentabilidade ambiental, das características da biodiversidade local e da solidez do agronegócio nacional, mas também do aumento dos investimentos em bioindústrias destinadas à fabricação de bioprodutos.

Bueno, Alvarez e Silva (2020) ressaltam a importância de estabelecer políticas públicas ligadas ao desenvolvimento da Bioeconomia, estrategicamente alinhadas ao alcance das dimensões da sustentabilidade. Para tanto, faz-se necessário que o desenvolvimento de inovações continue em bases da química verde (tecnologias renováveis e de baixa emissão de carbono), impactando fortemente os sistemas de agroindústria, com geração de empregos diretos e impactos positivos na demanda do setor rural brasileiro.

Quanto à questão de se utilizar resíduos decorrentes da atividade agroindustrial, observa Vaz Júnior (2020) que, ao mesmo tempo que a produção de biomassa gera uma grande quantidade de resíduos que exigem melhores abordagens e práticas técnicas e econômicas para reduzir seu impacto no meio ambiente e saúde pública. Tais resíduos podem gerar oportunidades para seu uso como matéria-prima industrial renovável, de acordo com os conceitos de química verde, Bioeconomia e economia circular, em estreita colaboração com os ODS, definidos pela Organização das Nações Unidas (ONU, 2015).

Com destaque, o agronegócio pode representar um elo primordial na integração de matérias-primas renováveis em seus processos produtivos, face à sua capacidade de operacionalizar a produção e distribuição de suprimentos agrícola. De acordo com Lins (2019), ao se referirem às indústrias de alimentos, apontam que este segmento é responsável por gerar toneladas de resíduos, acarretando sérios problemas ambientais, com a produção de lixo orgânico. Para eles, a Bioeconomia circular dos resíduos orgânicos e da indústria alimentícia vêm recebendo crescente atenção, já que estas matérias residuais representam recursos utilizáveis para a síntese de produtos úteis.

Hernández e Céspedes (2020), ao compreenderem a Bioeconomia como uma estratégia de sustentabilidade que se complementa e se fundamenta na quarta revolução industrial, consideram que a América Latina é reconhecida como um território com aptidão natural aos bens provenientes do agronegócio. Há nela um grande potencial para o desenvolvimento da Bioeconomia, como alternativa para a diversificação produtiva e agregação de valor bens oriundos dos setores agroindustriais. 
Para Rodrigues (2018), o uso de alta tecnologia para alterar processos produtivos, ao longo da cadeia agroindustrial, tornando-os mais sustentáveis, é a principal força motora da Bioeconomia, representando uma das fronteiras mais importantes da Quarta Revolução Industrial, em que tecnologias físicas, biológicas e digitais fundem-se para moldar o futuro. A Quarta Revolução Industrial terá como principal característica uma economia baseada na substituição de recursos não renováveis e na aplicação do modelo econômico da Bioeconomia Sustentável (STOCK, 2014).

Sousa Jabbour et al. (2018) argumentam que, a despeito dos conceitos da agroindústria 4.0 e economia circular não serem abordados de forma conjunta na literatura, as tecnologias inseridas no contexto da agroindústria 4.0 possuem a capacidade de preparar o caminho para os princípios da economia circular. Assim, elas podem, por exemplo, realizar o rastreamento de produtos pós-consumo para a recuperação de componentes. Uma organização descentralizada e orientada para a sustentabilidade, no contexto da economia circular e de fábricas inteligentes, concentra-se na alocação eficiente de produtos, materiais, energias e recursos hídricos (BLUNCK; WERTHMANN, 2017).

Para Martinho \& Avilez (2019), uma Bioeconomia circular e sustentável permite a maximização do valor dos recursos pelo maior tempo possível, por meio do uso da biomassa em cascata e valorização de subprodutos e biorresíduos. Esse processo é potencializado pelo uso de novas tecnologias, equilibrando fluxos de recursos renováveis, concretizando o potencial de redução de emissões associadas ao uso de produtos de base biológica e à manutenção em um ciclo fechado. Segundo os mesmos autores, tais abordagens induzem não só ganhos adicionais na redução de consumos de energia e emissões, mas também otimizam o sequestro de carbono, aumentando a resiliência às alterações climáticas.

O quadro 3 sintetiza os elementos chaves da reflexão trazida até aqui, relacionada aos alinhamentos das abordagens teóricas e das respectivas proposições tecnológicas da Bioeconomia, economia circular e agroindústria 4.0 para o sequestro de carbono, respondendo assim à anunciação da problemática central formulada, na parte introdutória. A proposição científica emergente Bioeconomia sustentável é adicionada ao quadro, em função dos resultados obtidos ao longo da revisão bibliográfica.

Conforme Graedel (1996), a insustentável crise climática desencadeou o surgimento de um novo paradigma, denominado de ecologia industrial, dedicado ao objetivo de que o planeta deve se desenvolver de forma sustentável. As tecnologias utilizadas na indústria 4.0 auxiliam no compartilhamento e armazenamento de informações em tempo real ao longo do ciclo de vida 
dos produtos (DANTAS et al., 2018), possibilitando a inclusão de ações que se adequam à economia circular. A implementação de uma economia circular será tanto mais fácil quanto se explorar as tecnologias e mudanças que emergirão por meio da quarta revolução industrial (BLUNCK; WERTHMANN, 2017). Decisões gerenciais para operações sustentáveis contribuem para uma melhor conexão entre os princípios da economia circular e as proposições tecnológicas da indústria 4.0 (SOUSA JABBOUR et al., 2018). Se assim for, caminha-se em direção a uma eficiência holística de recursos, no sentido de considerar a economia circular como uma das vantagens essenciais da agroindústria 4.0 (BLUNCK; WERTHMANN, 2017).

Quadro 3 - Alinhamentos entre as abordagens teóricas, as proposições tecnológicas da Bioeconomia, Bioeconomia sustentável, economia circular e agroindústria 4.0 para com o sequestro de carbono

\begin{tabular}{|c|c|c|c|c|}
\hline $\begin{array}{l}\text { Abordagem } \\
\text { conceitual }\end{array}$ & $\begin{array}{l}\text { Proposição } \\
\text { Conceitual }\end{array}$ & $\begin{array}{l}\text { Proposições } \\
\text { tecnológicas }\end{array}$ & $\begin{array}{l}\text { Estratégias } \\
\text { tecnológicas }\end{array}$ & $\begin{array}{c}\text { Alinhamento } \\
\text { com o } \\
\text { sequestro de } \\
\text { carbono }\end{array}$ \\
\hline Bioeconomia & $\begin{array}{l}\text { Substituição de } \\
\text { energia fóssil por } \\
\text { energia renovável }\end{array}$ & $\begin{array}{c}\text { Uso das } \\
\text { biomassas }\end{array}$ & $\begin{array}{c}\text { Dirigidas à redução } \\
\text { das emissões dos } \\
\text { GEE }\end{array}$ & $\begin{array}{c}\text { Relativamente } \\
\text { alinhada }\end{array}$ \\
\hline $\begin{array}{l}\text { Bioeconomia } \\
\text { Sustentável }\end{array}$ & $\begin{array}{l}\text { Substituição de } \\
\text { energia fóssil por } \\
\text { energia renovável }\end{array}$ & $\begin{array}{c}\text { Potencialização } \\
\text { dos } \\
\text { conhecimentos } \\
\text { da biotecnologia } \\
\text { e amparada pelas } \\
\text { TICT }\end{array}$ & $\begin{array}{l}\text { Dirigidas à redução } \\
\text { das emissões dos } \\
\text { GEE, no entanto, } \\
\text { atenta à superação } \\
\text { dos desafios ODS }\end{array}$ & $\begin{array}{c}\text { Positivamente } \\
\text { alinhada }\end{array}$ \\
\hline $\begin{array}{l}\text { Economia } \\
\text { Circular }\end{array}$ & $\begin{array}{l}\text { Maximização da } \\
\text { (re)utilização dos } \\
\text { insumos, matérias } \\
\text { primas, dentro de } \\
\text { uma racionalidade } \\
\text { econômica e } \\
\text { ambiental }\end{array}$ & $\begin{array}{l}\text { Reuso dos } \\
\text { resíduos, perdas e } \\
\text { sobras dos } \\
\text { materiais, insumos } \\
\text { e energias }\end{array}$ & $\begin{array}{l}\text { Dirigidas à redução } \\
\text { das emissões dos } \\
\text { GEE, face a menor } \\
\text { extração dos recursos } \\
\text { naturais, insumos, } \\
\text { matérias primas e } \\
\text { energias }\end{array}$ & $\begin{array}{c}\text { Relativamente } \\
\text { alinhada }\end{array}$ \\
\hline $\begin{array}{c}\text { Agroindústria } \\
4.0\end{array}$ & $\begin{array}{l}\text { Utilização das } \\
\text { ferramentas } \\
\text { digitais na } \\
\text { otimização da } \\
\text { gestão da cadeia } \\
\text { produtiva de } \\
\text { alimentos } \\
\text { funcionais, fibras e } \\
\text { energias }\end{array}$ & $\begin{array}{l}\text { Rastreamento do } \\
\text { ciclo produtivo da } \\
\text { agricultura e da } \\
\text { criação de } \\
\text { animais, no } \\
\text { atendimento da } \\
\text { segurança } \\
\text { alimentar e } \\
\text { nutricional }\end{array}$ & $\begin{array}{l}\text { Dirigidas à redução } \\
\text { das emissões dos } \\
\text { GEE, com vistas aos } \\
\text { interesses dos } \\
\text { agentes econômicos } \\
\text { ligados ao setor de } \\
\text { agronegócio }\end{array}$ & $\begin{array}{c}\text { Relativamente } \\
\text { alinhada }\end{array}$ \\
\hline
\end{tabular}

Fonte: Os autores (2021). 
Diante do exposto, há de se refletir sobre o desenvolvimento de estratégias de inovação intensivas em conhecimento para os setores agrícola e agroindustrial, uma vez que este modelo alternativo de desenvolvimento envolve o fundamento da inicial da Bioeconomia, em transição para a vertente da Bioeconomia sustentável, fomentando a biotecnologia e outras tecnologias facilitadoras, favorecendo o desenvolvimento em produtos bioenergéticos, diversificando a base econômica das economias regionais, internalizando ao longo do processo produtivo e nas linhas de produções as proposições tecnológicas da economia circular. Todas essas providências estratégicas e forma de pensar em um outro modelo societal colocarão a agroindústria 4.0 num outro patamar, com práticas mais sustentáveis, um modo de mitigar os efeitos negativos derivados das mudanças climáticas. Diante da revisão bibliográfica foi possível refletir sobre o alinhamento existente entre as abordagens teóricas e as respectivas proposições tecnológicas da Bioeconomia, da economia circular e da agroindústria 4.0, para o sequestro de carbono.

\section{Considerações finais}

Este ensaio teórico dedicou-se a refletir sobre os alinhamentos das abordagens teóricas e as respectivas proposições tecnológicas da Bioeconomia, da economia circular e da agroindústria 4.0, para o sequestro de carbono. Em função do delineamento da pesquisa proposta, que envolveu uma revisão bibliográfica, foi possível alcançar o objetivo declarado, dada à anunciação da problemática central colocada na parte introdutória. Nela questionava-se sobre as abordagens conceituais dos três termos e as abrangências deles para com as transições tecnológicas emergentes, voltadas para a mitigação da crise do clima, ultimamente denominada de emergência climática.

Conforme revisto, as variações do clima representam uma séria ameaça para a produção de alimentos, com segurança alimentar e nutricional e de novas fontes de energias imprescindíveis para o desenvolvimento das regiões. No que diz respeito à produção agrícola e na criação de animais, as mudanças climáticas constituem efetivamente uma forte ameaça sobre os fatores biológicos de produção, da resiliência dos ecossistemas vulneráveis sobre os quais estão assentadas as produções da agroindústria. Com vistas à cadeia produtiva alimentícia, quaisquer alterações nos níveis de produção ou mesmo de qualidade dos bens alimentícios acarreta uma séria de impactos de ordem econômica, social, ambiental e também no consumo de calorias e proteínas vegetais e animais. 
Quanto às abordagens teóricas e às respectivas proposições tecnológicas da Bioeconomia, da economia circular e da agroindústria 4.0, para o sequestro de carbono, foi possível refletir sobre a existência de um relativo alinhamento entre a Bioeconomia com a economia circular, bem como essas duas com a agroindústria 4.0. Também foi possível identificar conjuntos de alinhamentos positivos ao sequestro de carbono, com vistas à mitigação da emergência climática, intrínsecos nas três proposições tecnológicas.

Todas elas trazem por natureza, o uso e reuso racional dos recursos naturais disponíveis nos vulneráveis ecossistemas sobre os quais assentam as cadeias produtivas de alimentos e de energias, bem como os resíduos das linhas de produções e dos elos que integram todo o sistema agroindustrial. Ao longo da pesquisa, foi possível refletir sobre a transição da inicial proposição da Bioeconomia para a vertente Bioeconomia sustentável, uma vez que por si só produzir biomassas, bens biológicos renováveis, converte-se numa condição necessária, mas não necessariamente suficiente para que o sistema de produção seja eficazmente sustentável. A Bioeconomia sustentável é aquela que busca a substituição da energia fóssil pela bioenergia atendendo, contudo, às dimensões do princípio da sustentabilidade, cumprindo assim os Objetivos do Desenvolvimento Sustentável que propõem atingimento de metas específicas para o sequestro de carbono, um meio para mitigar os efeitos das mudanças do clima.

Igualmente, foi refletivo que a economia circular busca romper com o pensamento da economia linear. Ela está baseada nos conceitos relativamente ligados aos recursos materiais e energéticos, propondo a restauração, o reparo, o reuso, a remanufatura, a reciclagem e a superciclagem. O ciclo proposto pela economia circular representa um modelo regenerativo, sob o qual reinsere resíduos no ciclo produtivo e permite o alongamento da vida útil dos recursos, potencializando a reutilização ótima, bem como a retenção dos resíduos ou mesmo as sobras na economia pelo máximo de tempo possível.

São ações mitigadoras os sistemas de extração e de deposição no ambiente e, logo, das emissões dos GEE, das contínuas e extensas extrações e depilações dos recursos naturais e biológicos. Não obstante, a junção dos conceitos da Bioeconomia e economia circular ainda é um desafio quando se trata dos setores econômicos possivelmente alcançados e a competitividade econômica da reciclagem orgânica, além da vulnerabilidade dos preços de commodities agrícolas e minerais negociados no mercado internacional.

No que tange à relação existente entre Bioeconomia e agroindústria 4.0, foi possível analisar a implementação de uma Bioeconomia digital, por meio de uma produção inteligente e sustentável, de base biológica, em diversas cadeias produtivas e com utilização avançada de TIC, 
congregando os mundos físico, digital e biológico. A agroindústria 4.0 também pode contribuir para a economia circular, ao possibilitar o rastreamento, em tempo real, do produto durante todo o seu ciclo de vida, inclusive pós-consumo. Além disso, a agroindústria 4.0 permite a concretização do objetivo da economia circular, qual seja, a alocação eficiente de recursos, de forma holística. Portanto, vislumbra-se vantagens relacionadas à concretização de uma Bioeconomia circular e amparada pelos conceitos da agroindústria 4.0.

Metas de redução de resíduos por meio do seu reuso no ciclo de produção são fundamentais para o desenvolvimento de uma economia sustentável, maior eficiência na utilização de recursos e redução de resíduos, com menores emissões associadas ao GEE, potencializando o sequestro de carbono. Uma Bioeconomia sustentável e circular evitam o uso de carbono fóssil adicional, permitindo o atingimento de metas climáticas e de sequestro de carbono, mitigando os efeitos da crise climática. Com a Bioeconomia sustentável, verifica-se ainda ações de sequestro de carbono diretamente relacionadas à mudança de padrão de uso de energia fóssil para bioenergias renováveis.

Embora, nem todos os setores industriais possam abarcar, ao mesmo tempo, os conceitos e características das três proposições tecnológicas da Bioeconomia, economia circular e agroindústria 4.0; é possível, com base na tecnologia da informação intensiva da agroindústria 4.0: planejar o ciclo da economia circular com uso de Bigdata e em tempo real; rastrear, em tempo real, o produto durante todo o seu ciclo de vida, inclusive pós-consumo; planejar a cadeia produtiva bioeconômica, avaliar seu potencial e calcular o nível de descarbonização; e promover a digitalização e automação das cadeias produtivas bioeconômicas. São estas as considerações a tornarem-se objetos de reflexões entre os pares da academia e dos tomadores de decisões para a produção de bens alimentícios e de novas fontes de energia, direcionadores básicos do desenvolvimento das regiões.

\section{Referências}

ABDALLA, Fernando Antônio; SAMPAIO, Antônio Carlos Freire. Os novos princípios e conceitos inovadores da Economia Circular. Revista Entorno Geográfico. n. 2, v. 15, p. 82-102. 2018.

ALBERTIN, Alberto Luiz; ALBERTIN, Rosa Maria de Moura. A Internet das coisas irá muito além das coisas. GVEXECUTIVO, v 16, n 2, mar/abril. 2017.

ALVES, José Eustáquio Diniz. Os 25 anos da CIPD: Terra inabitável e o grito da juventude.

Revista Brasileira de Estudos de População, v.36, p. 1-13. 2019.

ASSOCIAÇÃO BRASILEIRA DE NORMAS TÉCNICAS (ABNT). ABNT NBR 6023 - Informação e documentação - Referências - Elaboração. 2. ed. Rio de Janeiro, 2018. 
BERALDO, Antonio Donizeti. Bioeconomia no Brasil: desafios e potencialidades. AgroANALYSIS, v. 38, n. 9, p. 24-25. 2019.

BERTALANFFY, Ludwig von. Teoria geral dos sistemas. 8. ed. Petrópolis-RJ: Vozes, 2015.

BLUNCK, Erskin; WERTHMANN, Hedwig. Industry 4.0-an opportunity to realize sustainable manufacturing and its potential for a circular economy. In: DIEM: Dubrovnik International Economic Meeting. Sveučilište u Dubrovniku, p. 644-666. 2017.

BOSCOV, Camila Pereira Boscov; REZENDE, Gabriel Ribeiro Vieira. Processo de Implementação do IFRS: um ensaio teórico sobre as justificativas relacionadas a resistências às mudanças organizacionais sob a teoria de Lewin. Revista de Educação e Pesquisa em Contabilidade (REPeC), v.10, n. 4, p. 449-465, out/dez. 2016.

BRASIL. Ministério da Ciência, Tecnologia, Inovações e Comunicações (MCTIC). Plano de Ação em Ciência, Tecnologia e Inovação em Bioeconomia. Brasília-DF: CGEE, 2018.

Secretaria de Políticas para a Formação e Ações Estratégicas. Coordenação-Geral do Clima. Estimativas anuais de emissões de gases de efeito estufa no Brasil. Coordenação-Geral do Clima. 5. ed. Brasília-DF: Ministério da Ciência, Tecnologia, Inovações e Comunicações, 2020a.

Ministério da Agricultura, Pecuária e Abastecimento (MAPA). Coletânea de fatores de emissão e remoção de gases de efeito estufa da pecuária brasileira. Brasília-DF: MAPA/SENAR, 2020b.

BONONI, Daniele Fernanda; POLLI, Henrique Quero. Aplicabilidade da ferramenta FMEA na mitigação de falhas de processos produtivos da agroindústria 4.0. Revista Interface Tecnológica, v. 17, n. 2, p. 513-522. 2020.

BUENO, Carolina da Silveira; ALVAREZ, Larissa Carolina Barboza; DA SILVA, Grazielle Cardoso. Redes e fronteiras tecnológicas em instituição de pesquisa: há um caminho sendo construído para o desenvolvimento rural da Bioeconomia? Cadernos de Ciência \& Tecnologia, v. 1, n. 1, p. 26776. 2020.

BUNDESMINISTERIUM FUR WIRTSCHAT UND ENERGIA (BMWI). O que é a Indústria 4.0? 2020. Disponível em <https://www.plattform-

i40.de/PI40/Navigation/DE/Industrie40/WasIndustrie40/was-ist-industrie-40.html>. Acesso em: ago. 2020.

CARRION, Patrícia; QUARESMA, Manuela. Internet da Coisas (IoT): Definições e aplicabilidade aos usuários finais. HFD, v. 8, n. 15, p. 49-66, mar. 2019. Disponível DOI:

http://dx.doi.org/10.59652316796308152019049.

CARUS, Michael; DAMMER, Lara. The circular bioeconomy-concepts, opportunities, and limitations. Industrial biotechnology, v. 14, n. 2, p. 83-91. 2018.

CEPEA. Centro de Estudos Avançados em Economia Aplicada. Mercado de trabalho do agronegócio brasileiro: aspectos metodológicos. Piracicaba, 2017.

COELHO, Pedro Miguel Nogueira. Rumo à indústria 4.0. (Dissertação de Mestrado). Faculdade de Ciência e Tecnologia. Universidade de Coimbra-PT. Portugal, 2016.

COMISSÃO MUNDIAL SOBRE MEIO AMBIENTE E DESENVOLVIMENTO (CMMAD). Nosso Futuro Comum. 2. ed. Rio de Janeiro: Editora Fundação Getúlio Vargas, 1991.

CONFEDERAÇÃO NACIONAL DA INDÚSTRIA (CNI); HARVARD BUSINESS REVIEW-BRASIL (HBRBR). Bioeconomia: Uma Agenda para o Brasil. Brasília-DF, 2013. 
Projeto Indústria 2027. Riscos e oportunidades para o Brasil diante de inovações

disruptivas. Estudo de Sistema Produtivo. Agroindústrias. Foco Setorial: Alimentos Processados. Brasília-DF: CNI, 2018.

D'AMATO, D.; et al. Green, circular, bio economy: A comparative analysis of sustainability avenues, Journal of Cleaner Production, volume 168, p. 716-734, dez. 2017.

DANTAS, Marina Kolland; PASSADOR, Cláudia Souza. Programa Município VerdeAzul: Uma análise integrada da gestão ambiental no estado de São Paulo. Revista Organizações \& Sociedade (0\&S), 27(95), p. 820-854. 2020.

DANTAS, Thales Eduardo Tavares; et al. Convergências entre as práticas da Indústria 4.0 e os princípios da Economia Circular. Anais [...]. XX Engema - USP-SP, São Paulo - SP, 2018.

DE ANDA-LÓPEZ, Rosa María; BETANZOS-CASTILLO, Francisco; SÁNCHEZ-SALINAS, Agripín; AGUIRRE-ARANDA, Rodolfo. Chapter 4 Application of simulation models in agricultural mechatronic design for Agroindustry 4.0. Modeling of the seed dosing system for automatic germination tray seed drill. Universidad Tecnológica del Sur del Estado de México, Disponível: DOI: 10.35429/H.2020.5.61.77.

DIREÇÃO GERAL DAS ATIVIDADES ECONÔMICAS (DGAE). Economia Circular. 2020. Disponível em <https://www.dgae.gov.pt/servicos/sustentabilidade-empresarial/economia-circular.aspx>. Acesso em: 25 ago. 2020.

DIAS, Rodnei Fagundes; CARVALHO FILHO, CAADE. Bioeconomia no Brasil e no mundo: panorama atual e perspectivas. Revista Virtual de Química, v. 9, n. 1. 2017.

ELKINGTON, John. Canibais com garfo e faca. São Paulo: Makron Books, 2001.

ELLEN MACARTHUR FOUNDATION. What is Circular Economy? 2020. Disponível em: $<$ https://www.ellenmacarthurfoundation.org/circular-economy/what-is-the-circulareconomy>. Acesso em: jan. 2021.

EUROPEAN COMISSION. Comunicação da comissão ao parlamento europeu, ao conselho, ao comité económico e social europeu e ao comité das regiões. Fechar o ciclo: Plano de Ação da UE para a Economia Circular. Comunidade Europeia, 2015.

. Comunicação da comissão ao parlamento europeu, ao conselho, ao comité económico e social europeu e ao comité das regiões. Uma Bioeconomia sustentável na Europa: Reforçar as ligações entre a economia, a sociedade e o ambiente. CE, 2018.

EUROPEAN PARLIAMENT. União Europeia, 2016. Indústria 4.0. Disponível em <https://www.europarl.europa.eu/RegData/etudes/STUD/2016/570007/IPOL_STU(2016)57000 7_EN.pdf.> Acesso em: ago. 2020.

FEDERAÇÃO DAS INDÚSTRIAS DO ESTADO DO RIO DE JANEIRO (FIRJAN). Panorama da Inovação-Indústria 4.0. Internet das coisas. Rio de Janeiro: FIRJAN, 2016.

FEIX, R.D.; LEUSIN JÚNIOR, S. Estatísticas e indicadores do emprego formal do agronegócio: nota técnica. Porto Alegre: FEE, 2016.

FOSTER, Allan; ROBERTO, Samanta Souza; IGARI, Alexandre Toshiro. Economia circular e resíduos sólidos: uma revisão sistemática sobre a eficiência ambiental e econômica. Anais [...]. Engema - USP-SP, São Paulo - SP, 2016.

GARCÍA-BAQUERO, Ricardo Domínguez. Agroindustria 4.0, la era de la información y la conectividad. Mercacei magazine, n. 104, p. 56-61. 2020. 
GEISSDOERFER, Martin; et al. The Circular Economy-A new sustainability paradigm? Journal of cleaner production, v. 143, p. 757-768. 2017.

GEORGESCU-ROEGEN, Nicholas. Energy and economic myths. Southern economic journal, p. 347-381. 1975.

GIL, Antonio Carlos. Como elaborar projetos de pesquisa. 6. ed. São Paulo: Atlas. 2017.

GONÇALVES, Ana Carolina; NEIVA, Kalil Nascimento; LOPES, José Carlos de Jesus; VASCONCELOS, Alexandre Meira de. Abordagens sobre Bioeconomia na Produção Científica Qualificada. Anais [...]. XXII Engema. USP-SP. São Paulo, nov., 2020.

GRAEDEL, Thomas E. On the concept of industrial ecology. Annual Review of Energy and the Environment, v. 21, n. 1, p. 69-98. 1996.

HEIJMAN, Wim. How big is the bio-business? Notes on measuring the size of the Dutch bioeconomy. NJAS-Wageningen Journal of Life Sciences, v. 77, p. 5-8. 2016.

HENNING, Kagermann. Recommendations for implementing the strategic initiative Industrie 4.0. 2013. Disponível em:

<https://www.knaw.nl/shared/resources/actueel/bestanden/26_10_2012_Henning\%20Kagerm ann.pdf>. Acesso em: mar. 2021.

HERNÁNDEZ, R. E.; CÉSPEDES, J. Bioeconomía: una estrategia de sostenibilidad en la cuarta revolución industrial. Revista de Investigación e Innovación Agropecuaria y de Recursos Naturales, v. 7, n. 2, p. 126-133. 2020.

INSTITUTE FOR EUROPEAN ENVIRONMENTAL POLICY (EIP-AGRI). The Role of Agriculture and The Forestry in The Circular Economy. Workshop on circular economy. Finlândia: Institute for European Environmental Policy (IEEP), 2015.

JAPIASSÚ, Hilton. Interdisciplinaridade e patologia do saber. Rio de Janeiro: Imago, 1976.

LAMPIS, Andrea; TORRES, Pedro Henrique Campello; JACOBI, Pedro Roberto; LEONE, Ana Lia. A produção de riscos e desastres na América Latina em um contexto de emergência climática. $\mathbf{O}$ Social em Questão, n. 48, set/dez, p. 75-96. 2020.

LEFF, Enrique. Saber ambiental: sustentabilidade, racionalidade, complexidade, poder. 10. ed. Petrópolis, RJ: Vozes, 2013.

LEWANDOWSKI, Iris. Bioeconomy: Shaping the transition to a sustainable, biobased economy. Springer Nature, 2018.

LINS, Amanda Barbosa. Produção de bioemulsificante por Rhodotorula mucilaginosa UCP 1551 através da Bioeconomia circular utilizando substratos agroindustriais. Dissertação, 67 p. Universidade Católica de Pernambuco. Recife - PE, 2019.

MARCIAL, Elaine C.; et al. Brasil 2035: cenários para o desenvolvimento. Brasília-DF: IPEA, 2017. MARCONI, Marina de Andrade e LAKATOS, Eva Maria. Técnicas de pesquisa: planejamento e execução de pesquisa, amostragens e técnicas de pesquisa, elaboração, análise e interpretação de dados. 8. ed. São Paulo: Atlas, 2018.

MARTINHO S \& AVILLEZ F (2019). O Acordo de Paris, a neutralidade carbónica e a

Bioeconomia. Cultivar. Cadernos de Análise e Prospetiva e Prospetiva № 15 23-29 pp. Gabinete de Planeamento, Políticas e Administração Geral (GPP). ISBN 2183-5624.

MASSRUHÁ, Silvia Maria Fonseca Silveira; et al. Agricultura digital: pesquisa, desenvolvimento e inovação nas cadeias produtivas. Brasília - DF: Embrapa, 2020. 
MCCORMICK, Kes; KAUTTO, Niina. The bioeconomy in Europe: An overview. Sustainability, v. 5, n. 6, p. 2589-2608. 2013.

MEJIAS, Rafael Gouveia. Bioeconomia e suas aplicações. R. ÎANDÉ Ciências e Humanidades. São Bernardo do Campo, v. 2, n. 3, p. 105-121, jul. 2019.

MENEGUETTI, F. K. O que é ensaio-teórico? Revista Administração Contemporânea, v. 15, n. 2, p. 320-332, abr. 2011.

MOLESTI, Romano. I fondamenti della Bioeconomia. La nuova economia ecológica. Franco Angeli: Milan, Italy, 2006.

MOREIRA, Alexandre M. Bioeconomia: Plataforma Mundial de Inovação e Sustentabilidade nas Cadeias Agroindustriais. Revista Processos Químicos, v. 10, n. 20, p. 351-353. 2016.

MORIN, Edgar. Introdução ao Pensamento Complexo. 4. ed. Lisboa-Portugal: Instituto Piaget, 2003.

MORRAR, Rabeh; ARMAN, Husam; MOUSA, Saeed. The fourth industrial revolution (Industry 4.0): A social innovation perspective. Technology Innovation Management Review, v. 7, n. 11, p. 12-20. 2017.

NASCIMENTO, Paulo Tromboni de Souza. Um ensaio teórico de caracterização objetiva e crítica do conceito de Administração. Cadernos Ebape.BR. v. 12, no 2, p. 206-220, abr./jun. 2014.

NILES, M. T.; LUBELL, M. Integrative frontiers in environmental policy theory and research. Policy Studies Journal, p. 41-64. 2012.

NOBRE, C. A.; et al. Ministério do Meio Ambiente (MMA). Secretaria de Biodiversidade e Florestas-SBF, Diretoria de Conservação da Biodiversidade-DCBio. Mudanças climáticas e possíveis alterações nos biomas da América do Sul. Relatório, n. 6, p. 25. 2007.

OLIVEIRA, Denise Leonardo Custodio Machado de. Desenvolvimento e especialização da agroindústria em Uberlândia-MG (1970 a 2014): a expansão das indústrias processadoras de soja, carnes e couros e seu papel na articulação das escalas local-global. Tese, p. 223. Universidade Estadual Paulista, Rio Claro - SP, 2016.

ORGANISATION FOR ECONOMIC CO-OPERATION AND DEVELOPMENT (OECD). 2009. The Bioeconomy to 2030: Designing a Policy Agenda, OECD Publishing, Paris. Disponível DOI: https://doi.org/10.1787/9789264056886-en.

ORGANIZAÇÃO DAS NAÇÕES UNIDAS (ONU). Plataforma Agenda 2030.0s Objetivos do Desenvolvimento Sustentável (ODS). 2015. Disponível em: <http://www.agenda2030.com.br>. Acesso em: dez, 2020.

Onu News/Perspectiva Global e Reportagens Humanas. 2021. Emergência Climática. Disponível em: <https://news.un.org/pt/tags/emergencia-climatica>. Disponível em: abr., 2021. OLIVEIRA, Lilian Ribeiro de; PASSADOR, Cláudia Souza. Ensaio teórico sobre as avaliações de políticas públicas. Cadernos Ebape.BR. v. 17, no 2, p. 324-337, abr./jun. 2019.

PARRÉ, José Luiz. O agronegócio nas macrorregiões brasileiras: 1985 a 1995. Tese de Doutorado. Universidade de São Paulo. São Paulo -SP, 2000.

PORTUGAL. COTEC. Bioeconomia Circular e Digital: Oportunidades para a Transição e Desenvolvimento Sustentável da Economia e Indústria Portuguesa. Porto: COTEC, 2019. 
Resolução do Conselho de Ministros. RCM n. 190-A, de 11 de dezembro de 2017, que aprovou o Plano de Ação para a Economia Circular (PAEC). Diário da República, no 236, 2017. Disponível em: <https://dre.pt/application/conteudo/114337039>. Acesso em: nov. 2020.

RIBEIRO, Luana Silva. Inovação Cradle to Cradle (C2C) e circularidade: contribuições econômicas e ambientais no Brasil. Revista Iniciativa Econômica, v. 4, n. 1. 2018.

RODRIGUES, Meghie. Bioeconomia é a nova fronteira para o futuro da América Latina. Ciência e Cultura, v. 70, n. 4, p. 21-22. 2018.

SACHS, Ygnacy. Caminhos para o desenvolvimento sustentável. 2. ed. Rio de Janeiro: Garamond, 2002.

SANTOS, Andreia Brasil; ROCHA, Jannyelle Sousa; MAFRA, Rosana Zau; FERREIRA, Marcio Antônio Couto. A relevância da Bioeconomia para o desenvolvimento regional: Estudo de caso em uma empresa de biocosméticos do estado do Amazonas. Anais [...]. 58ㅇ Congresso Sober, 2020. Foz do Iguaçu, 2020.

SANTOS, Kelly Cristina Monteiro dos. Análise de práticas sustentáveis nos setores administrativos de uma agroindústria de laticínios do sertão da Paraíba. Dissertação, 40 p. Universidade Federal de Campina Grande. Campina Grande - PB, 2018.

SEHNEM, Simone; PEREIRA, Susana Carla Farias. Rumo à Economia Circular: Sinergia Existente entre as Definições Conceituais Correlatas e Apropriação para a Literatura Brasileira. Revista Eletrônica de Ciência Administrativa, v. 18, n. 1, p. 35-62, 2019.

SILVA, João Batista da; PREZOTTO, Leomar Luiz. Programa de Agroindustrialização da Produção da Agricultura Familiar. Documento Referencial - Edição 2007-2010. Brasília - DF: Ministério do Desenvolvimento Agrário, 2007.

SILVA, Martim Francisco de Oliveira; PEREIRA, Felipe dos Santos; MARTINS, José Vitor Bomtempo. A Bioeconomia brasileira em números. 2018. NDES Setorial, v. 47, p. 277-332, $\mathrm{mar} / 2018$.

SILVA, Michele Lins Aracaty e; OLIVEIRA, Marcílio Lima de. A Bioeconomia como alternativa complementar ao modelo de desenvolvimento do Amazonas. Anais [...]. 58을 Congresso Sober, 2020. Foz do Iguaçu, 2020.

SOARES, Sandro Vieira; PICOLLI, Icaro Roberto Azevedo; CASAGRANDE, Jacir Leonir. Pesquisa Bibliográfica, Pesquisa Bibliométrica, Artigo de Revisão e Ensaio Teórico em Administração e Contabilidade. Revista RAEP. Rio de Janeiro, v. 19, n. 2, p. 308-339, mai-ago. 2018.

SOUSA JABBOUR, Ana Beatriz Lopes; et al. Industry 4.0 and the circular economy: a proposed research agenda and original roadmap for sustainable operations. Annals of Operations Research, v. 270, n. 1-2, p. 273-286. 2018.

SOUSA, Renata; TAIRA, G. R.; PARK, S. W. Integração do sistema ciber-físico para sistema de programação intertravamento e controle de um reator batelada. The Journal of Engineering and Exact Sciences, v. 5, n. 5, p. 0424-0432. 2019.

STAHEL, Walter R. The circular economy. Nature, v. 531, n. 7595, p. 435-438. 2016.

STAFFAS, Louise; GUSTAVSSON, Mathias; MCCORMICK, Kes. Strategies and Policies for the Bioeconomy and Bio-Based Economy: An Analysis of Official National Approaches. Sustainability, volume 5, p. 2751-2769, 2013. Disponível em: DOI:10.3390/su5062751.

STERN, N. What is the Economics of Climate Change. World Economics, v. 7, n. 2, april-june. 2006. 
STOCK, Nuala Ribeiro de Melo. Estudo comparativo de agendas para a Bioeconomia: conceitos, importância e estratégias. Trabalho de Conclusão de Curso. Universidade de São Paulo - USP, Lorena - SP, 2014.

STOCKER, Thomas F.; et al. Climate change 2013: The physical science basis. Contribution of working group I to the fifth assessment report of the intergovernmental panel on climate change. Cambridge University Review, v. 1535. 2013.

VASCONCELLOS, Maria José Esteves de. Pensamento Sistêmico: O novo paradigma da ciência. Campinas-SP: Papirus, 2002.

VAZ JUNIOR, Silvio. Aproveitamento de resíduos agroindustriais: uma abordagem sustentável. Brasília-DF: Embrapa Agroenergia, 2020.

VEIGA, José Eli da. Sustentabilidade: a legitimação de um novo valor. 2. ed. São Paulo, SP: Senac-São Paulo, 2011.

VELEVA, Vesela; BODKIN, Gavin; TODOROVA, Svetlana. The need for better measurement and employee engagement to advance a circular economy: Lessons from Biogen's "zero waste" journey. Journal of Cleaner Production, v. 154, p. 517-529. 2017.

VOGT, Mara; BILK, Ângela; SILVA, Márcia Zanievicz. Incerteza ambiental na contabilidade gerencial: Perspectivas futuras. Pretexto, v. 20, n.4, p. 45-59, out-dez, 2019.

WBCSD, E. ACCENTURE. Conselho Empresarial Brasileiro para o Desenvolvimento Sustentável (CEBDS). CEO guide to the circular economy. Geneve, Suisse, 2017. 